\title{
Antepartum Cortical Vein Thrombosis
}

\author{
${ }^{1}$ Anjana Vaidyanathan, ${ }^{2} \mathrm{~S}$ Bhuvana
}

\section{ABSTRACT}

Cortical vein thrombosis is a rare antepartum diagnosis. Here we present a case report of a patient successfully managed throughout her pregnancy till puerperium.

Keywords: Cortical venous thrombosis, High-risk pregnancy, Seizures.

How to cite this article: Vaidyanathan A, Bhuvana S. Antepartum Cortical Vein Thrombosis. J South Asian Feder Obst Gynae 2017;9(2):200-202.

\section{Source of support: Nil}

Conflict of interest: None

Date of received: 7 January 2017

Date of acceptance: 7 March 2017

Date of publication: April 2017

\section{INTRODUCTION}

The first description of cortical vein thrombosis (CVT) is attributed to the French physician Ribes, who in 1825 observed thrombosis of the sagittal sinus and cerebral veins in a man who had suffered from seizures and delirium. ${ }^{1}$ The annual incidence is estimated to be 5 per 100,000 population. ${ }^{2}$ The incidence is found to be higher in women owing to gender-specific predisposing factors like pregnancy, puerperium, and oral contraceptive pills. ${ }^{3}$ The frequency of CVT in puerperium is found to be 12 cases per 100,000 deliveries. It occurs most often in the third trimester or postpartum. ${ }^{2}$ However, we received the patient with a radiological diagnosis of CVT in the second trimester at 22 weeks. She was evaluated for prothrombotic state and found to be anti-Rho and anti-La positive. We discuss here about the risk factors, evaluation, diagnosis, management, and follow-up of the patient with CVT.

${ }^{1}$ Junior Resident, ${ }^{2}$ Associate Professor

1,2Department of Obstetrics and Gynecology, Sri Ramachandra Medical College and Research Institute, Chennai, Tamil Nadu India

Corresponding Author: Anjana Vaidyanathan, Junior Resident, Department of Obstetrics and Gynecology, Sri Ramachandra Medical College and Research Institute Chennai, Tamil Nadu, India, Phone: +919003176637, e-mail: anjanavaid@gmail.com

\section{CASE REPORT}

A 20-year-old primigravida, 22-week housewife presented in the outpatient department as a diagnosed case of CVT for further management.

The patient was first admitted after the first episode of generalized tonic-clonic seizure at 9 weeks 5 days in another hospital. The magnetic resonance imaging (MRI) scan showed thrombosis of straight, inferior sagittal, transverse, sigmoid sinuses with temporoparieto-occipital hemorrhagic infarct due to dural sinus thrombosis (Fig. 1). Patient was started on an injectable anticoagulant (Enoxaparin) and oral antiepileptics. On evaluation of the thrombogenic state, antinuclear antibody (ANA; anti-Rho and anti-La) was found positive. All other prothrombotic markers were found to be negative. Rheumatology opinion was obtained and the patient was started on Tab. Hydroxychloroquine and Tab. Aspirin $75 \mathrm{mg}$ once a day. At 17 weeks, the patient was readmitted with status epilepticus as she was not taking phenytoin regularly owing to hyperemesis. Repeat MRI showed partial recanalization of the transverse and sigmoid sinus (Fig. 2). At 22 weeks, the patient was admitted for evaluation in our hospital and had a seizure episode, which was conservatively managed with IV antiepileptic medication. Baseline investigations were done and found to be normal and vitals were found to be stable. Anomalies were ruled out by ultrasound and fetal echo was done, as the patient was ANA positive, and found to be normal. Patient was discharged with advice to follow the same medication, following which the patient came for regular antenatal checkups. At 36 weeks, the patient came to the emergency room with history of one episode of seizure, after being subjected to trauma. The patient was observed in the labor room and started on IV antiepileptics. Inj. heparin was stopped and an elective lower-segment cesarean section was planned at 37 weeks. But the patient went into spontaneous labor and delivered by assisted vaginal delivery for obstetric indication (outlet forceps). Postnatally, the patient had no residual neurological deficit. The baby was evaluated for conduction defects and found to be structurally normal. Neurology opinion and rheumatology opinion was obtained at discharge and the patient was asked to continue oral antiepileptics and heparin for 6 weeks. On follow-up, her puerperal period was uneventful. 


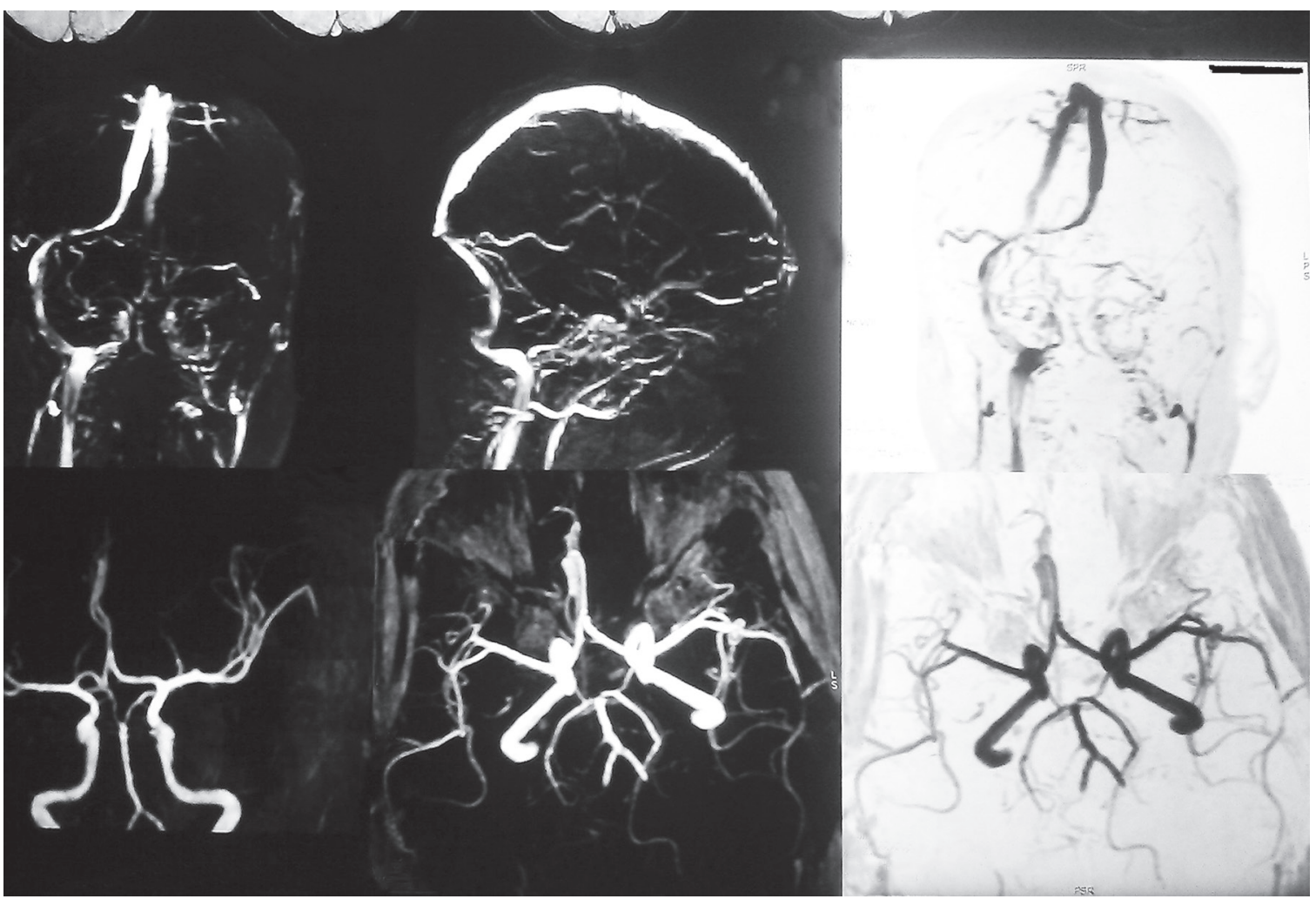

Fig. 1: Thrombosis of straight, inferior sagittal, transverse, sigmoid sinuses

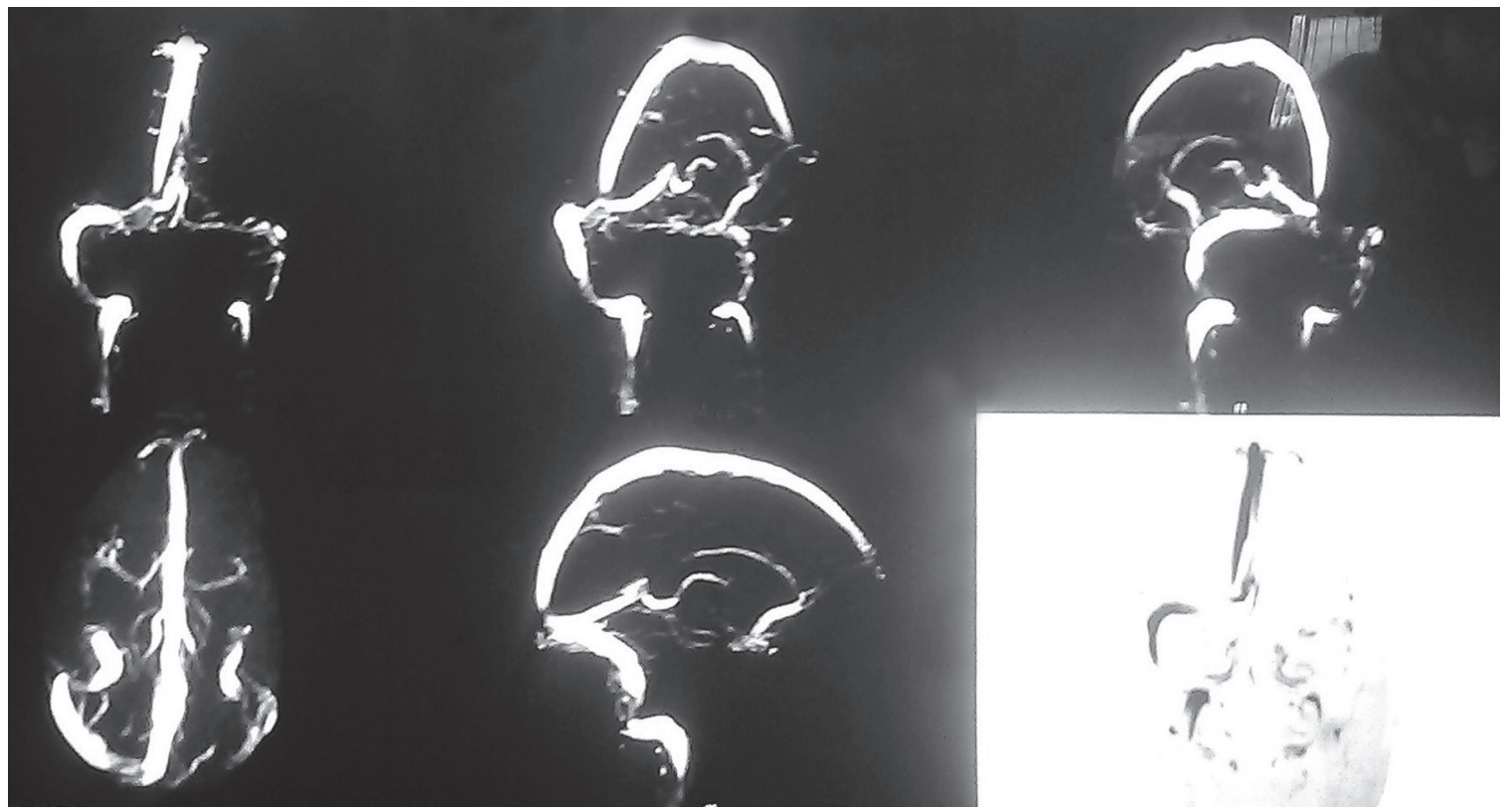

Fig. 2: Partial recanalization of transverse and sigmoid sinus

\section{DISCUSSION}

Cortical vein thrombosis must be considered in any woman presenting with neurological manifestations during pregnancy and puerperium, ${ }^{2,4}$ in any trimester of pregnancy. The diagnosis of CVT is usually by a combination of clinical suspicion and radiological confirmation. Patients usually present with headache, visual disturbances, and seizures. ${ }^{2,5}$ As evidenced by this case, pregnant women presenting with cerebral venous thrombosis should be evaluated for thrombogenic state and any underlying cause, if present, must also be simultaneously treated. The diagnostic modality of choice is MRI with venography. ${ }^{5-7}$ Once the diagnosis is confirmed, the treatment involves the use of antiepileptics and anticoagulants. ${ }^{2,6}$ In our case, an addition of diseasemodifying antirheumatic drugs was used in view of the 
ANA-positive state. Even in the presence of predisposing factors like hyperemesis and history of trauma, which prompted the episodes of seizure, such patients can be effectively managed, with close monitoring, in a tertiary care hospital with multidisciplinary effort, involving the neurology, rheumatology, and obstetrics departments.

\section{CONCLUSION}

With early recognition and confirmation of diagnosis based on high degree of clinical suspicion and initiation of prompt and vigilant treatment with antiepileptics and anticoagulants, CVT can be successfully managed during pregnancy and puerperal state.

\section{REFERENCES}

1. Ribes MF. Des recherches faites sur la phlebite. Revue Medical Francais et Etrangere er Journal de clinique del 'Hotel Dieu et de la Charite de Paris 1825;3:5.

2. Saposnik G, Barinagarrementeria F, Brown RD Jr, Bushnell CD, Cucchiara B, Cushman M, deVeber G, Ferro JM, Tsai FY,
American Heart Association Stroke Council and the Council on Epidemiology and Prevention. Diagnosis and management of cerebral venous thrombosis: a statement for healthcare professionals from the American Heart Association / American Stroke Association. Stroke 2011 Apr;42(4):1158-1192.

3. Coutinho JM, Ferro JM, Canhão P, Barinagarrementeria F, Cantú C, Bousser MG, Stam J. Cerebral venous and sinus thrombosis in women. Stroke 2009 Jul;40(7):2356-2361.

4. Cantu C, Barinagarrementeria F. Cerebral venous thrombosis associated with pregnancy and puerperium. Review of 67 cases. Stroke 1993 Dec;24(12):1880-1884.

5. Appenzeller S, Zeller CB, Annichino-Bizzachi JM, Costallat LT, Deus-Silva L, Voetsch B, Faria AV, Zanardi VA, Damasceno BP, Cendes F. Cerebral venous thrombosis: influence of risk factors and imaging findings on prognosis. Clin Neurol Neurosurg 2005 Aug;107(5):371-378.

6. Demir CF, Inci MF, Ozkan F, Yildiz M, Ozdemir H. Clinical and radiological management and outcome of pregnancies complicated by cerebral venous thrombosis: a review of 19 cases. J Stroke Cerebrovasc Dis 2013 Nov;22(8):1252-1257.

7. Zhou Q, Wang F, Zhang P, Long X, Sun X, Liu T. Clinical characteristics and outcomes of cerebral venous sinus thrombosis during pregnancy and puerperium. Zhonghua Fu Chan Ke Za Zhi 2010 May;45(5):358-362. 